Portland State University

PDXScholar

7-16-1997

\title{
The Effect of Lymph Sac Pressure on Lymph Heart Pressure Development in the Toad Bufo marinus
}

Michael Georgitsis

Portland State University

Follow this and additional works at: https://pdxscholar.library.pdx.edu/open_access_etds

Part of the Biology Commons

Let us know how access to this document benefits you.

\section{Recommended Citation}

Georgitsis, Michael, "The Effect of Lymph Sac Pressure on Lymph Heart Pressure Development in the Toad Bufo marinus" (1997). Dissertations and Theses. Paper 5359.

https://doi.org/10.15760/etd.7232

This Thesis is brought to you for free and open access. It has been accepted for inclusion in Dissertations and Theses by an authorized administrator of PDXScholar. Please contact us if we can make this document more accessible: pdxscholar@pdx.edu. 
THESIS APPROVAL

The abstract and thesis of Michael Georgitsis for the Master of Science in Biology were presented on July 16,1997 , and accepted by the thesis committee and the department.

COMMITTEE APPROVALS:

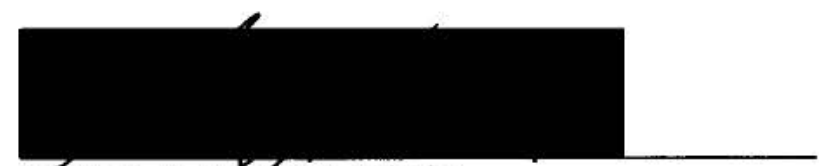

Stanley S. Hilman, Chair

Larry I. Cfawshaw

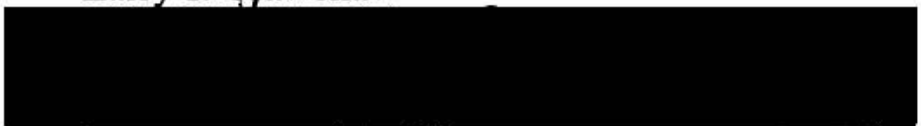

Randy Zelick 0

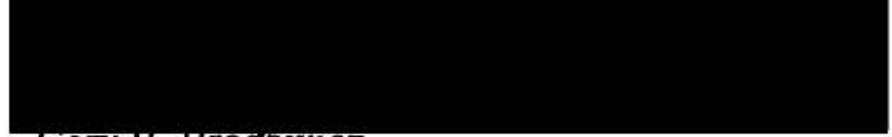

Gary R. Broowicz

Representative of the office of Graduate Studies

DEPARTMENT APPROVAL:

Leonard Simpson, Chair

Department of Biology

ACCEPTED FOR PORTLAND STATE UNIVERSITY BY THE LIBRARY

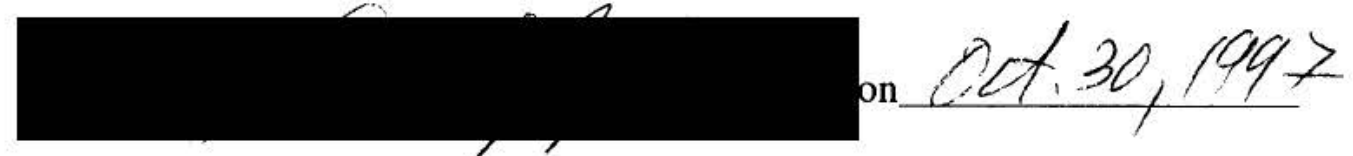




\begin{abstract}
An abstract of the thesis of Michael Georgitsis for the Master of Science in Biology presented July $16,1997$.
\end{abstract}

Title: The effect of lymph sac pressure on lymph heart pressure development in the toad Bufo marinus.

Lymph hearts play an important role in blood volume regulation in anurans by controlling the movement of fluid from the lymphatic spaces to the vasculature. The anatomical continuity between lymph sacs and lymph hearts predicts a coupling of pressure between the two structures which may represent a physical basis for lymph heart regulation. The precise relationship between lymph heart pressure and lymph heart output was not examined so that conclusions regarding changes in work performed by the hearts as a result of changing lymph sac pressure could not be made. However, increases in lymph sac pressure led to increases in both diastolic and systolic pressures generated by the hearts. A given rise in lymph sac pressure also led to a proportionally larger increase in diastolic pressure than systolic pressure.

The rates of pressure development were examined in relation to increasing lymph sac pressure and it was found that diastolic pressure decreases were more rapid with increased lymph sac pressure indicating that filling of the hearts was enhanced. The filling of the lymph hearts is passive, and under higher pressure, this occurs more rapidly.

An increase in lymph sac pressure led to a decrease in the maximum rate of systolic pressure development. This suggests that the lymph hearts may have become over distended by excessive filling such that contraction was impeded. The fact that 
the rapidity of systolic pressure development decreased when lymph sac pressure was elevated provides evidence that the load on the heart was increased but that the hearts were not necessarily responding to this load by ejecting the fluid any more vigorously.

Examining the effects of lymph sac pressure on lymph heart pressure development allowed passive and active components of the lymph heart pressure trace to be distinguished. Diastolic pressures demonstrated a closer correlation to increased lymph sac pressure than did systolic pressures. It remains unresolved whether this constitutes a basis for physical regulation of the lymph hearts as work output was not directly measured. 


\title{
THE EFFECT OF LYMPH SAC PRESSURE ON LYMPH HEART PRESSURE DEVELOPMENT \\ IN THE TOAD BUFO MARINUS.
}

\author{
by \\ MICHAEL GEORGITSIS
}

A thesis submitted in partial fulfillment of the requirements for the degree of

\section{MASTER OF SCIENCE \\ in \\ BIOLOGY}

Portland State University

1997 


\section{TABLE OF CONTENTS}

\section{PAGE}

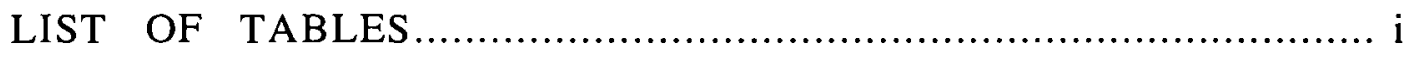

LIST OF FIGURES ............................................................ ii

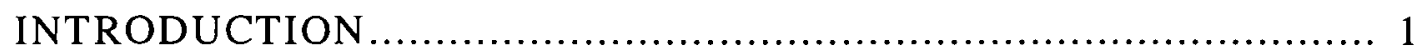

MATERIALS AND METHODS .................................................. 18

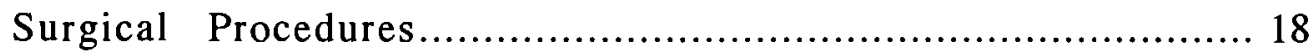

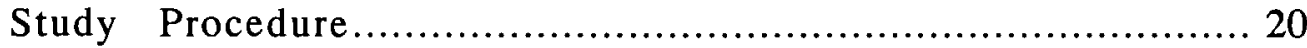

Lateral lymph sac infusion.............................................. 21





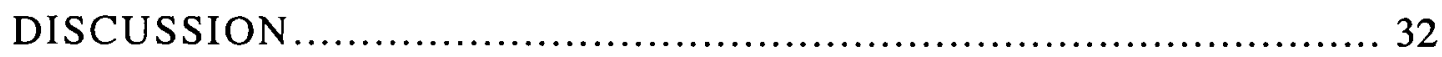

LITERATURE CITED ............................................................. 36 


\section{LIST OF TABLES}

TABLE

PAGE

I Diastolic and systolic pressure slopes during infusion.............. 26

II Left and right lymph heart pressure correlation slopes.............. 30 


\section{LIST OF FIGURES}

FIGURE

PAGE

1 Interfemoral lymph sac, lymph heart and venous pressure against time in a $306 \mathrm{~g}$ toad.

2a Lymph heart and lymph sac pressure during infusion

experiment.

$2 b \quad$ Venous pressure in the ventral abdominal vein during

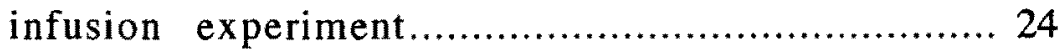

3 Systolic pressure and lymph sac pressure during infusion........... 25

4 Diastolic pressure and lymph sac pressure during infusion.......... 25

5 The most rapid increases in lymph heart pressure regressed

with lymph sac pressure.

6 The most rapid decreases in lymph heart pressure regressed

with lymph sac pressure.

$7 \quad$ Systolic pressure regressed with maximal rates of lymph heart

pressure increases

8 Diastolic pressure regressed with maximal rates of lymph heart pressure decreases...................................... 29

$9 \quad$ Lymph heart rate during infusion experiments.................... 31 


\section{INTRODUCTION}

The environment occupied by amphibians necessitates the development of physiological adaptations that are effective in the transition zone between aquatic and terrestrial conditions. Amphibian skin, being highly water permeable, provides an ineffective barrier against evaporative water flux. Consequently, xeric conditions invariably lead to dehydration while aquatic conditions result in net water uptake due to the hyperosmotic concentration of the tissues. Behavioral and morphological traits may account for certain differences in the relative ability to withstand the environmental challenges of water balance, but from a physiological perspective amphibians are faced with the rapid movement of water into or out of their bodies. This rapid exchange of water between the organism and its environment has important consequences for mechanisms involved in blood volume regulation. The amphibian lymphatic system is especially important in this regard as it has been shown to be responsible for rapid shifts of fluid between interstitial and vascular spaces.

Under aquatic conditions, an osmotic gradient exists favoring net influx of water, and measurements of cutaneous water uptake have been made in several anuran species. In the cane toad Bufo marinus, cutaneous water uptake under hydrated conditions was determined to be approximately $30 \mathrm{ml} \mathrm{kg}^{-1} \mathrm{hr}^{-}$ ${ }^{1}$ (Shoemaker, 1965). Measurements of water influx across the pelvic patch region have also been made, and these have been determined to be $0.6 \pm 0.2 \mathrm{ml} \mathrm{cm}^{-2} \mathrm{hr}^{-1}$ for Bufo marinus and $0.02 \pm 0.003 \mathrm{ml} \mathrm{cm}^{-2} \mathrm{hr}^{-1}$ for Scaphiopus couchii toadlets under hydrated conditions (Parsons et al., 1993; Jones, 1978). Water influx rates 
vary interspecifically, and have been shown to range from $2 \%$ body weight $\mathrm{hr}^{-1}$ in Xenopus laevis adults to $30 \%$ body weight $\mathrm{hr}^{-1}$ in Scaphiopus couchii toadlets under hydrated conditions (Ewer 1952, Jones, 1978).

Cutaneous water influx increases significantly with dehydration. In dehydrated Bufo marinus, water uptake increases to approximately $130 \mathrm{ml} \mathrm{kg}^{-1} \mathrm{hr}^{-1}$, a 400\% higher rate than that of hydrated control conditions (Shoemaker 1965). Similarly, dehydration in Scaphiopus couchii toadlets leads to a 15 -fold increase in water uptake across the pelvic patch (Jones 1978). These changes in rates of water uptake are not solely a direct consequence of increases in osmotic gradient since a comparatively slight increase in body fluid concentration elicits a much greater increase in cutaneous water influx. Dehydration has been shown to result in a hydroosmotic response where endocrine control regulates the permeability and blood flow in both the integument and bladder so that the net effect is to increase water influx rates and decrease fluid lost by urination.

Hormones involved in the mediation of the hydroosmotic response include arginine vasotocin (AVT), angiotensin II, and certain B-adrenergic effectors. Arginine vasotocin is secreted by the neurohypophysis in response to decreased blood volume and stimulates increased skin and bladder permeability, effectively restoring blood volume and completing a negative feed-back loop (Christensen, 1975). Angiotensin II has been implicated in the regulation of cutaneous water uptake across the pelvic patch in Bufo marinus with respect to bladder volume. Cutaneous water uptake decreases with bladder distention but administration of angiotensin II has been shown to increase water uptake across the pelvic patch in a dose dependent manner when the bladder was filled experimentally with Ringer's solution (Parsons 
et al.1993). Bladder distention presumably results in decreased angiotensin II which reduces cutaneous water uptake. In Bufo punctatus, angiotensin II has also been shown to stimulate behavioral water absorption where an increased frequency in pressing of the pelvic patch on moist surfaces was observed (Brekke et al., 1991). Adrenergic involvement has also been identified in the anuran hydroosmotic response. Isoproterenol, a B-adrenergic agonist, has been shown to elicit increased cutaneous water uptake in hydrated Bufo cognatus with greater magnitude than the response observed with arginine vasotocin (Yokota and Hillman, 1984).

The physical path taken by fluid moving from the external environment into the organism suggests an important regulatory function of the subcutaneous lymph sacs. Incoming fluid can traverse the integument directly and enter the lymphatic space. Conversely, capillaries present within the integument could absorb the fluid directly into the circulatory system, but if hydrostatic forces exceed the colloid osmotic pressure of the plasma proteins then Starling's theory predicts net loss of fluid from the circulatory system (Conklin, 1930a). In either situation, the incoming fluid accumulates in the capacious lymphatic sacs beneath the skin. It remains unresolved as to which of these routes is responsible for the larger portion of volume flux, but investigations tracing the path of tritiated water have shown that the label was more rapidly detected in the lymph, and then later in the plasma (Wentzell et al., 1993).

Early studies of the anuran lymphatic system provide meticulous anatomical detail, describing the various components in relation to musculo-skeletal features. Ecker (1889) described the components as being lymph vessels and spaces between organs, subcutaneous lymph sacs, and lymph hearts. The septated lymph sacs, and 
their various boundaries, as well as the location, and number of lymph hearts is given in great detail, but Ecker examined these only in Rana esculenta.. The nature of the valves separating the various lymph sacs was also investigated, and found to be muscular in Rana esculenta, Rana temporaria, and Bufo bufo (Jolly 1946). More recently, the gross morphology of subcutaneous lymph sacs was examined in a number of anuran species from diverse habitat in an attempt to establish patterns of interspecific variation. Specimens of seventeen species were examined, and these included representatives from the genera Ascaphus, Bufo, Cyclorana, Heleioporus, Limnodynastes, Litoria, Mixophyes, Neobatrachus, Notaden, Rana and Xenopus. It was found that species with larger lymph sacs tended to inhabit aquatic habitats while those with smaller sacs tended to occupy more terrestrial locations (Carter, 1979). The anatomical configuration of the various subcutaneous lymph sacs also varied interspecifically despite some basic similarities. The direction of fluid flow between the various lymph sacs was investigated by tracing the path of colored dyes, and it was found that a one-way valve system between the septated sacs led to fluid ultimately being collected into the lateral lymph sacs from other body lymph sacs (Carter, 1979 and Rodrigues, 1957).

Fluid in the various lymph sacs is returned to the general circulation by means of lymph hearts (Priestley, 1878). The number of lymph hearts in anuran amphibians vary interspecifically, where at least one anterior pair is present, but the posterior pairs vary in number depending on maturity, where the number is typically higher in larval stages (Kampmeier,1969). Each of the anterior lymph hearts is located lateral to the transverse process of the third vertebra beneath the scapula, and receive lymph from adjacent anterior lymph sinuses through afferent ostia. These hearts then expel 
lymph through a single efferent pore into the anterior vertebral vein, a branch of the internal jugular vein (Kampmeier, 1969). The posterior lymph hearts, when present in a single pair as in Bufo, are located more superficially, on either side of the urostyle in the angles formed by the convergence of the coccyx and iliac bones. Lymph from the posterior portions of the dorsal, iliac, and cardinal lymph sinus flows through afferent pores into the posterior lymph heart (Jolly, 1946; Kampmeier, 1969). The posterior lymph heart pumps lymph into the posterior vertebral vein which in turn connects to the iliac veins (Kampmeier, 1969). The valves of the lymph hearts have been examined and the afferent valves have been found to be muscular and help prevent the efflux of lymph back into the lymph sac during contraction. The efferent valves which open into the venous circulation, have been found to be nonmuscular (Jolly, 1946). The number of valves in the walls of the adjacent lymph sacs also increases in number near the posterior lymph hearts (Jolly, 1946). These hearts are covered by the ilio-coccygea fascia, and muscle fascicles extend beneath it to anchor it to connective tissue of the skin (Kampmeier, 1969; Priestley, 1878). During contraction, the elasticity of the connective tissue allows the anchoring fibers to stretch, but at diastole, the fibers return to their original length, such that the heart becomes dilated (Conklin, 1930b). Innervation to the anterior and posterior lymph hearts is by the szcond and tenth spinal ncrves respectively (Priestley, 1878).

The embryological development of anuran lymph hearts has been examined in Bufo vulgaris and it has been found that the mode of genesis differs between the anterior and posterior lymph hearts (Kampmeier, 1969). The development of the anterior lymph heart begins at a stage when there is no histological differentiation 
between arteries, veins, and lymphatics. It originates dorsal to the pronephros from a plexus of venolymphatic channels which forms in conjunction with the 3rd and 4rth intersegmental blood vessels. Individual channels within the plexus expand, and surrounding mesenchymal cells align themselves outside the endothelium to produce the future contractile coat. The developing lymph heart then transiently severs connection to vessels except for the terminal portion of the 3rd intersegmental vein, and continues to grow and assume a globular shape. The heart then reestablishes connection with a newly formed afferent lymphatic vessel of the lateral line. At this time a single afferent valve is present, but this number increases to five once the tadpole has undergone metamorphosis. The efferent valve at the lymphaticovenous junction is formed from a circular endothelial cushion protruding into the venous lumen (Kampmeier, 1969).

The development of posterior lymph hearts is similar to that of anterior lymph hearts in that a transient detachment also occurs between the heart and afferent vessels, but its development begins at a later stage where the afferent vessels have already differentiated into lymphatics (Kampmeier, 1969). Lymph vessels within a plexus located lateral to the posterior vertebral vein at the level of the 11th intersegment merge and expand while surrounding mesenchymal cells align themselves to form the future contractile coat. The developing heart then detaches from the lymph vessels to later reconnect with lymph vessels of the lateral line with simultaneous valve development. The efferent valve at the lymphaticovenous junction is also formed at this time (Kampmeier, 1969).

The wall of lymph hearts is composed of three layers: the inner tunica intima, the intermediate tunica media, and the outer tunica externa. Flattened endothelial cells 
supported by cross striated collagen fibers make up the lining of the tunica intima. The thickness of these endothelial cells has been measured in Bufo bufo japonicus and Hyla arborea and found to range from 0.2 to $1.3 \mu \mathrm{m}$ when excluding the nuclear region (Satoh, 1980; Liu Zhi-yu, 1989). The tunica media is primarily composed of striated muscle cells showing some branching. The muscle cells run in various directions and have well developed sarcoplasmic reticulum. Upon contraction, a myofiril composed of 3 to 8 sarcomeres is shortened to $10 \%$ of its original relaxed length (Satoh, 1980). The tunica externa is mainly composed of fibroelastic tissue containing blood vessels, bundles of myelinated nerve fibers and free cells such as fibroblasts, chromatophores, lymphocytes and granular leucocytes (Satoh, 1980). Inlet valves were also observed and found to be adluminal elongations of the intimal tissue with numerous smooth muscle cells. Even though certain unmyelinated nerve fibers were distributed within the subendothelial connective tissue of the valve, no nerve endings were found in close association with the smooth muscle cells (Satoh, 1980).

Blood vessel permeability to proteins is important in determining whether plasma proteins remain in the vasculature, and Starling recognized in 1894 that the capillaries in mammalian liver and intestinal mucosa are permeable to proteins. In such a situation, an increase in hydrostatic pressure results in both fluid and protein loss which prevents total blood volume restoration through colloid osmotic forces alone, and a subsequent outpouring of lymph results. The skin capillaries of the frog Rana pipiens have been shown to be permeable to protein, and fluid from the blood is continually lost into the lymphatic spaces. Plasma proteins found in the lymph include fibrinogen, albumins, and globulins (Conklin, 1930c).Transcapillary fluid 
exchange in isolated toad hind limbs has been investigated, and it has been found that blood capillaries in amphibian skeletal muscle are comparatively much less resistant to transcapillary fluid movement than mammalian skeletal muscle . Capillary isogravimetric pressure, the blood pressure at which there is no net loss or gain of fluid across the capillary, was measured to be $2.92 \pm 0.24 \mathrm{~cm} \mathrm{H_{2 }} \mathrm{O}$ in the toad as compared with a range from 12 to $23 \mathrm{~cm} \mathrm{H}_{2} \mathrm{O}$ in various mammals (Smits and Ilowite, 1989). The capillary filtration coefficient which is a measure of fluid flow out of the capillary when capillary blood pressure is raised was measured to be 0.216 $\pm 0.012 \mathrm{ml} \mathrm{min}^{-1} \mathrm{~cm} \mathrm{H}_{2} \mathrm{O} 100 \mathrm{~g}^{-1}$ in toads, a value approximately ten times higher than mammalian measurements (Smits and Ilowite, 1989). This indicates that capillary fluid loss can occur at a lower hydrostatic pressure in amphibians and that for a given change in capillary blood pressure, the amphibians lose much more fluid from their capillaries than do mammals. In addition, the colloid osmotic pressure difference between plasma and lymph in mammalian skeletal muscle averages around


amphibians system lacks a comparatively large driving force for reabsorption (Baldwin, 1993).

There are several methods for fluid to be absorbed into the vasculature, and the effectiveness of each varies according to physiologic conditions. Transcapillary exchange is significant when the balance of Starling's forces remain favorable for fluid reabsorption, but increased capillary permeability to proteins, and decreased perfusion of blood vessels set limitations to the amount of fluid that can be reabsorbed in this way. Experiments were performed to examine the changes in transcapillary fluid forces during dehydration to determine the effectiveness of this 
method of fluid uptake under such conditions. It was found that Bufo marinus, as the more dehydration-resistant species was able to maintain plasma volume during early dehydration more effectively than the more aquatic Rana catesbeiana (Hillman et al., 1987). Under conditions of dehydration, the concentration of sodium and protein in the plasma, as well as hematocrit increased leading to a larger colloid osmotic pressure. Interstitial fluid pressure also became more negative so that the osmotic gradient favoring fluid uptake did not necessarily increase. In addition, arterial pressure decreased while venous pressure remained constant in both species so that no determinations could be made regarding changes in hydrostatic forces (Hillman et al., 1987). A study examining the pattern of water apportionment in amphibians found that aquatic species of amphibians, including Rana catesbeiana tended to have a uniform distribution of water in the various body compartments as a group, but that Bufo marinus as a more terrestrial species had $5 \%$ less total body water, $8 \%$ less intracellular fluid volume, and $3 \%$ more extracellular fluid volume than the aquatic species (Thorson, 1964).

Other methods for mobilizing fluid to the vasculature include absorption of water from the bladder as previously described in the hydroosmotic response where the permeability of the bladder wall is variable and regulated by the hormone AVT. The bladder, which may represent 20 to $50 \%$ of the body weight when full, is also an important source of sodium ions which can be actively transported into the circulatory system. This active transport of sodium is enhanced by the presence of the hormones aldosterone, insulin, and epinephrine (Shoemaker and Nagy, 1977). The relative contribution of fluid from the bladder in maintaining plasma volume can be eliminated by emptying the bladder prior experimentation, and when this was 
done, plasma volume was still maintained to a greater extent in the dehydration resistant species, but for shorter duration. Storage of fluid in the bladder seems to be more important for long-term survival, when water in not available in the environment.

Ciliated peritoneal funnels provide yet another method for returning lymphatic fluid to the vasculature, but is thought to be of minor importance when considering the total volume of lymph return. Scanning electron microscopy (SEM) has shown that between 600 to 800 ciliated peritoneal funnels open onto the ventral surface of each kidney in the toad Bufo marinus (Morris, 1981). The peritoneal cavity is in direct communication with subcutaneous lymph sacs and is connected by peritoneal funnels to the renal veins. The flow through the peritoneal funnels has been indirectly determined to be $0.50 \mathrm{ml} \mathrm{hr}^{-1}$ based on calculations relying on the compliance of the funnels where the time taken for a known volume to produce a certain pressure was measured. Addition of arginine vasotocin also resulted in a $40 \%$ increase in the pressure generated by the funnels, but this was thought to be due to decreased compliance as the vessels constricted, and not due to enhanced flow. The pressures generated, even after addition of arginine vasotocin, never exceeded $0.39 \mathrm{kPa}$ (Morris, 1981).

Probably the most significant route for returning lymphatic fluid to the vasculature involves the collection of lymph into various lymph sacs, and its subsequent pumping into the venous circulation. Both anterior and posterior lymph hearts, from their embryological development to their mature forms in adult anurans are located at the lymphaticovenous junction. Fluid flow occurs from a region of higher pressure to one of lower pressure, and measurements of subcutaneous 
interstitial fluid pressure have been made in several amphibians and found to be slightly negative, around $-2 \mathrm{~cm} \mathrm{H} \mathrm{H}_{2} \mathrm{O}$ for the toad Pipa americana. (Scholander, 1968). Venous pressure has also been measured in numerous anurans, and while being somewhat variable, is always positive and in the region of $+10 \mathrm{~cm} \mathrm{H}_{2} \mathrm{O}$. The pressure gradient at the lymphaticovenous junction thus favors flow from the venous circulation to the lymphatic system but the presence of the contractile lymph hearts in combination with a unidirectional valve allowing flow to the venous circulation allow for flow to occur from the lymphatics to the vasculature. Pressure development during the contractile cycle of posterior lymph hearts has been measured, as well as pressure inside adjoining lymph sacs and venous vasculature, and it has been observed that during a contractile cycle, the diastolic pressure dips below the pressure in the lymph sac and during systole, the pressure developed exceeds that of the venous circulation, making it possible for flow to occur into the vasculature. It is thus theoretically possible for the lymph hearts to return lymphatic fluid to the vasculature, but the most convincing evidence regarding the importance of lymph hearts in mobilizing fluid to the vasculature comes from experiments examining the consequences of their destruction.

Experiments were conducted where all 4 lymph hearts in the toad Bufo arenarum and the frog Leptodactyllus ocellatus were destroyed by thermocautery or paralysis by denervation. Within 3 to 4 days all the animals died after having progressively increased in weight by $20 \%$ daily, following surgery. An enormous accumulation of fluid was observed in lymph sacs, the peritoneal cavity, and in the tissues. Following lymph heart destruction, changes in the blood included decreased blood volume, increased hemolysis, increased hematocrit, a 30\% drop in arterial 
pressure, decreased kidney circulation, and a $30 \%$ decrease in urinary output. Once the lymph hearts were destroyed, it was not possible to prolong life by placing the animals in a dry environment or in a 8-10\% solution of $\mathrm{NaCl}$ (Foglia, 1941). Experiments were also conducted on Bufo marinus to determine the contribution of lymphatic pathways during recovery from hemorrhage and it was found that toads with destroyed lymph hearts were unable to acutely recover the lost blood volume and displayed progressive hemoconcentration until death in 1-3 days (Baustian, 1988). Apparently, fluid left the blood vessels and entered the lymphatics, but could not retum in adequate amounts. This provides evidence that lymphatic fluid is returned in greater quantities through the lymph hearts than through capillary reabsorption, but previous experiments had found that transcapillary filling could occur rapidly enough to account for hemodilution following blood loss (Middler, et al.1968). The three major routes for lymph return to the vascular space include transcapillary filling, lymph hearts and nephrostomes.

The formation of lymph has been studied in anuran amphibians and it has been found that lymph is produced in comparatively large quantities, and returned rapidly to the blood (Conklin, 1930ab). In Rana, the lymph hearts were found to pump a volume of fluid corresponding to 50 times that of a mammal of similar mass (Feder and Burggren, 1992). Numerous indirect measurements of lymph formation have been made by determining the amount of fluid passing through the lymph hearts, and the results varied considerably. Von Bruecke in Winterstein's Handbuch (in Conklin, 1930) estimated the stroke volume of the lymph heart to be $1 \mu l$ and with a constant heart rate of 60 beats per minute, determined that the four lymph hearts in an unnamed species of frog, with unspecified mass, pumped $14.1 \mathrm{ml} \mathrm{hr}^{-1}$. 
Baldwin, estimating the lymph heart stroke volume in Rana pipiens to be $0.5 \mu \mathrm{l}$, and the resting lymph heart rate to be 80 beats per minute found that lymph flow through four hearts in a $40 \mathrm{~g}$ frog was $240 \mathrm{ml} \mathrm{kg}^{-1} \mathrm{hr}^{-1}$ or $9.6 \mathrm{ml} \mathrm{hr}^{-1}$ (Baldwin, 1993). Radawaska (1906) similarly estimated the stroke volume to be $0.5 \mu \mathrm{l}$ and with a heart rate of 60 beats per minute calculated lymph flow to be $180 \mathrm{ml} \mathrm{hr}^{-1}$ (Kampmeier, 1969). Jones determined lymph flow to be $11.1 \mathrm{ml} \mathrm{kg}^{-1} \mathrm{hr}^{-1}$ in hydrated Bufo marinus at rest by cannulating individual lymph hearts, and collecting lymph over a known time period. In Jones' experiments, the lymph heart outflow pore was not occluded, but by lowering the cannula it was thought that lymph would be preferentially shunted through the cannula instead of flowing to the venous circulation (Jones et al., 1992). Isayama in 1924, conducted experiments where hematocrit changes were determined before and after lymph heart destruction, estimated total output to be $154 \mathrm{ml} \mathrm{kg}^{-1} \mathrm{hr}^{-1}$ (Jones et al., manuscript).

Indirect determinations of lymph production where estimates of lymph heart stroke volume are used, are problematic for several reasons. Firstly, even if the volume of the heart were accurately determined, there is no assurance that a given contraction will expel a volume comparable to the entire internal volume of the heart. In toads where only a single posterior lymph heart is present on each side of the urostyle, there is little differencc in size, but large size variations have been observed in various species of anuran amphibians. The African engystomatid frog, Breviceps verrucosus have comparatively enormous posterior lymph hearts 10 to $11 \mathrm{~mm}$ in length while measuring $38 \mathrm{~mm}$ from snout to vent. In contrast, the much larger Rana guppyi typically measuring over $200 \mathrm{~mm}$ from vent to snout possesses posterior lymph hearts $6 \mathrm{~mm}$ in length (Kampmeier, 1969). The number of posterior 
lymph hearts is also variable in adult anurans between species where Rana pipiens and Rana temporaria have 2 to 3 lymph hearts on each side; Rana esculenta have 2 to 4 , and Bufonids tend to have a single posterior lymph heart on each side (Kampmeier, 1969) The number of posterior lymph hearts is also variable within individuals, where observations have been made in adult Rana pipiens that have sometimes been shown to have differing numbers of hearts between the left and right side. In addition, the size of posterior lymph hearts within the same individual is not always constant (Kampmeier 1969). Even if lymph heart rate were constant, given the variability in number, and size, accurate estimates of lymph production based on stroke volume calculations is difficult. Direct measurements of lymph flow through the posterior lymph hearts under hydrated conditions have been made and determined to be $26 \pm 5 \mathrm{ml} \mathrm{kg}^{-1} \mathrm{~h}^{-1}$ in each heart. Stroke volume was measured to be $8.9 \pm 1.4$ $\mu \mathrm{l} \mathrm{kg}{ }^{-1}$. After 24 hours of dehydration, both flow and stroke volume decreased by $80 \%$ (Jones et al. manuscript, 1996).

The mechanisms for control of lymph heart function are hormonal, neuronal, or physical. Hormonal regulation has been investigated. Arginine vasotocin (AVT) has been found to decrease lymph heart rate by $25 \%$ while leaving lymph heart pressure unchanged (Parsons et al., 1994). AVT is normally released in response to dehydration and causes an increase in blood volume by increasing the permeability of the skin and and bladder to water. A decrease in lymph heart rate by AVT is controversial as this opposes the hydroosmotic response. It has also been found that when AVT is administered in concentrations within the physiologic range, an increase in lymph heart pressure is observed (DeGrauw, unpublished data). AVT also increases cilia beat frequency in the peritoneal funnels which contributes to 
blood volume expansion (Morris, 1981).

Severing the spinal nerves running to the lymph hearts results in cessation of contractions that is not always permanent (Priestley, 1878). Contractions are thought to be normally initiated by impulses conveyed through the spinal nerve fibers and a homolateral synchrony in lymph heart pulsations has been reported (Conklin, 1930a). However, experiments involving the transplantation of lymph hearts onto regions of the tongue have demonstrated that automaticity of lymph heart contraction occurs in the absence of innervation by spinal nerves (Satoh, 1980). Neuronal factors have been shown to be important in the control of lymph heart function. Pulmocutaneous baroreceptors have been found that provide feedback on arterial pressure and regulate lymph heart rate. Increased pressure in the arterial system results in a decrease in lymph heart rate effectively reducing the lymphatic contribution to the blood volume (Crossley, 1995). Stretch receptors in the carotid bifurcation as well as in the atrium are also thought to be involved in lymph heart regulation (Middler et al., 1968).

A third way in which lymph heart function may be regulated involves the effect of a physical load upon lymph heart contraction. Experiments investigating the mechanical factors involved in determining the output of the ventricles in the mammalian heart found that increased venous inflow resulted in increased output (Patterson and Starling, 1914). Starling also observed that an increased pressure on the input side led to an increased speed of filling, hence a decreased diastolic time and an increased speed of contraction. The metabolic rate of the heart was also measured by determining oxygen consumption rates and it was found that the metabolic rate increased with an increase in venous inflow. Starling observed that the isolated heart 
displayed adaptability with respect to the load so that the heart could alter its activity to meet the body's requirements. This adaptability still remained present once the nerves were destroyed and he concluded that the muscle fibers of the heart were involved in regulating this mechanism. An increased volume in the ventricles, as a result of increased inflow, leads to an increased length in muscle fiber and a subsequent increase in contraction strength. This allowed the output of the left ventricle to remain independent of arterial resistance as long as venous inflow remained constant. In summary, Starling formulated a law of the heart which states that the energy of contraction, however measured, is a function of the length of the muscle fiber (Starling, 1918).

The purpose of this thesis was to investigate the effect of lymph sac pressure on posterior lymph heart pressure development. Lymph heart pressure development was examined by analyzing changes in peak systolic, diastolic, and the rates $(\mathrm{dP} / \mathrm{dt})$ at which these pressures are reached. Although the anatomical configuration of the lymph hearts is significantly different from that of the hemal hearts in that inflow occurs under considerably lower pressure and through numerous afferent pores, it would be valuable to investigate whether lymphatic hearts respond to Starling's law of the heart. This would provide information on the physical regulation of the lymph heart and determine whether such a mechanism of adaptability to load applies to lymph hearts.

The nature of the load on the posterior lymph hearts can be described by determining the compliance of the adjacent lymph sacs leading into the hearts. Compliance provides a measure of distensibility and is defined as the quotient of volume to pressure in a compartment. Measurements of compliance have been made 
in the subcutaneous tissue compartments species of arboreal and non arboreal snakes, and it was found that arboreal snakes demonstrated significantly lower subcutaneous tissue compliance than their ground-dwelling counterparts (Lillywhite, 1993). Snakes exhibiting lower tissue compliance were better able to resist postural edema and differences in compliance reflected adaptive structural differences related to requirements for counteracting gravitational stresses. The measurement of compliance as an indicator of an adaptive structural feature can also be extended to amphibians with respect to fluid mobilization from the lymphatic space to the vasculature. It has already been demonstrated that the more aquatic species of anurans tend to have larger lymph sacs than more terrestrial species (Carter, 1979), and it would be beneficial to determine interspecific differences in lymph sac compliance and relate this to any trends in dehydration tolerance.

In order to determine the work done by the lymph hearts, it is necessary to measure the output flow which is the product of pressure and change in volume. Experiments were conducted on the toad Bufo marinus that directly measured the pressure and flow of the posterior lymph hearts (Jones et al. manuscript, 1996). It was observed that stroke volume was directly related to peak systolic pressure. This suggests that peak systolic pressure can be used as an indirect indicator of the work being performed by the lymph heart. The effect of lymph sac pressure on lymph heart pressure development can thus be examined to determine whether a physical mechanism of regulation is present. 


\title{
MATERIALS AND METHODS
}

\begin{abstract}
Animals
Specimens of adult Bufo marinus of both sexes (235-344 g) were obtained from commercial suppliers. These were kept unfed, at room temperature $\left(24 \pm 2{ }^{\circ} \mathrm{C}\right)$, with free access to water until experiments were conducted.
\end{abstract}

\section{Surgical Procedures}

The toads were anaesthetized by immersion into a solution of tricaine methane sulfonate (MS 222) until the corneal reflex was lost. This method of anaesthesia was repeated for all surgical procedures. Venous pressure was measured by inserting a non-occluding cannula, fitted with a T-tube $(P E-90$, deadspace $=0.20 \mathrm{ml})$ into the ventral abdominal vein. This allowed for venous pressure to be measured directly without completely disrupting flow. An incision $3.0 \mathrm{~cm}$ long, through the ventral integument was made. It began $3-4 \mathrm{~cm}$ anterior to the cloacal opening, and extended rostrally along but slightly offset from the midline. This exposed a layer of muscle (Rectus abdominis), beneath which the ventral abdominal vein could often be seen. Another incision was made slightly offset from the linea alba, and the ventral abdominal vein exposed. Suture loops (Nylon 2-0), were used to briefly stop blood flow while the cannula tips were inserted into the vein. These suture loops were then 
slipped along the length of the inserted cannulae and tightened to hold the vein in place. Muscle and skin layers were then separately sutured closed.

Pressures inside the posterior lymph hearts were measured directly by inserting a cannula $\left(\mathrm{PE}-10\right.$, deadspace $\left.=3.1 \times 10^{-3} \mathrm{ml}\right)$ inside the heart . The lymph hearts were located by examining the surface of the skin that lay $1-2 \mathrm{~cm}$ lateral to the urostyle, for rhythmical pulsations. Immersion into the anaesthetic solution of tricaine methane sulfonate (MS 222), well past the stage where the corneal reflex was lost, led to a decrease and cessation of lymph heart contractions making them more difficult to locate. Once located, a $1 \mathrm{~cm}$ incision was made directly above, and the skin held up and away from the pulsating lymph heart. By raising the skin, the attachments to the skin of the sheets of fascia covering the lymph heart became apparent, and channels leading to the pulsating, slightly pigmented heart could be observed. A $1.0 \mathrm{~mm}$ incision was made into the wall of the heart, and a flared tip PE10 cannula, filled with heparinized saline, was gently inserted so that it pushed through the incision. A purse string suture (Polypropylene 6-0) was used to secure the cannula in place. The skin was then closed.

The final surgical procedure involved cannulating the interfemoral lymph sac with two cannulae so that a volume of fluid could be infused while simultaneously measuring the pressure inside the lymph sac. A $2 \mathrm{~mm}$. incision was made along the midline beginning 1 to $2 \mathrm{~cm}$ anterior to the cloacal opening. A PE-90 cannula was adapted by inserting a cotton thread wick via procedures used by Scholander, Hargens, and Miller (1968). This helped ensure fluid continuity inside the cannula. The wick-cannula, and an empty cannula (PE-90, deadspace $0.027 \mathrm{ml}$, and $0.03 \mathrm{ml}$, respectively) were then inserted into the incision and secured by a purse string 
suture. This procedure was repeated on the lateral lymph sac. The cannulae were then flushed with heparinized saline and capped. The toad was then allowed to recover for 24 hours before experimentation.

\section{Study Procedure}

Pressures inside the lymph sacs, lymph hearts, and ventral abdominal vein were measured by connecting the cannulas to three pressure transducers. The transducers were connected to amplifiers on a NARCO Bio Systems physiograph (Physiograph six-B). The amplifiers were in turn connected to an Instrunet data acquisition board, (model No. 100) and data directly input into a Macintosh computer.

The pressure transducers were calibrated before and verified for consistency after each experiment. Calibration was accomplished by setting the ventral surface of the animal to be zero centimeters of water pressure, and raising the tips of the cannulas in ten centimeter increments and recording corresponding voltages. A conversion plot was then made where the slope and $y$-intercept were input into the superscope program so that voltage inputs could be displayed as pressures in centimeters of water. The lymph heart, lymph sac, and ventral abdominal vein cannulas were then flushed with heparinized saline $(0.8 \% \mathrm{NaCl})$ and connected to their corresponding pressure transducers. The animal was then placed in a covered container and allowed to rest before experiments were conducted. 
Lateral lymph sac infusions

A volume of saline $(0.8 \% \mathrm{NaCl})$, corresponding to $8 \%$ of the animal's mass, was measured into a syringe and fitted onto an infusion pump (Sage Instruments model No. 351). The flow rate was set at $10 \mathrm{ml} \mathrm{min}^{-1}$. The infusion pump was then connected to the non-wick cannula in the lateral lymph sac.

Recordings of lateral lymph sac, posterior lymph heart, and ventral abdominal vein pressures were then simultaneously made. Infusions were started five minutes after the beginning of recordings.

Interfemoral lymph sac infusions

The procedure used for the lateral lymph sac infusions was repeated, replacing the lateral lymph sac with the interfemoral lymph sac.

\section{Statistical analysis}

Linear correlation coefficients were used to examine the effect of lymph sac pressure on lymph heart pressure development. A probability level $p<0.05$ was used to identify statistical significance for all tests. A Wavemetrics Igor Pro program was used in the analysis. Student's $t$ test was used to determine the statistical difference in the compliances measured. 


\section{RESULTS}

The compliance of the lateral lymph sac was measured to be $3.90 \pm 0.736 \mathrm{ml}$ $\mathrm{kPa}^{-1} \mathrm{~kg}^{-1}$ ( \pm S.E.; $\mathrm{n}=8$ ). The compliance of the interfemoral lymph sac was measured to be $1.96 \pm 0.444 \mathrm{ml} \mathrm{kPa}^{-1} \mathrm{~kg}^{-1}( \pm$ S.E.; $n=9)$. The difference in compliance between the lateral and interfemoral lymph sacs was statistically significant $(p<0.05)$.

The pressures of the interfemoral lymph sac, posterior lymph heart and ventral abdominal from a representative individual are displayed against time in figure 1 below.

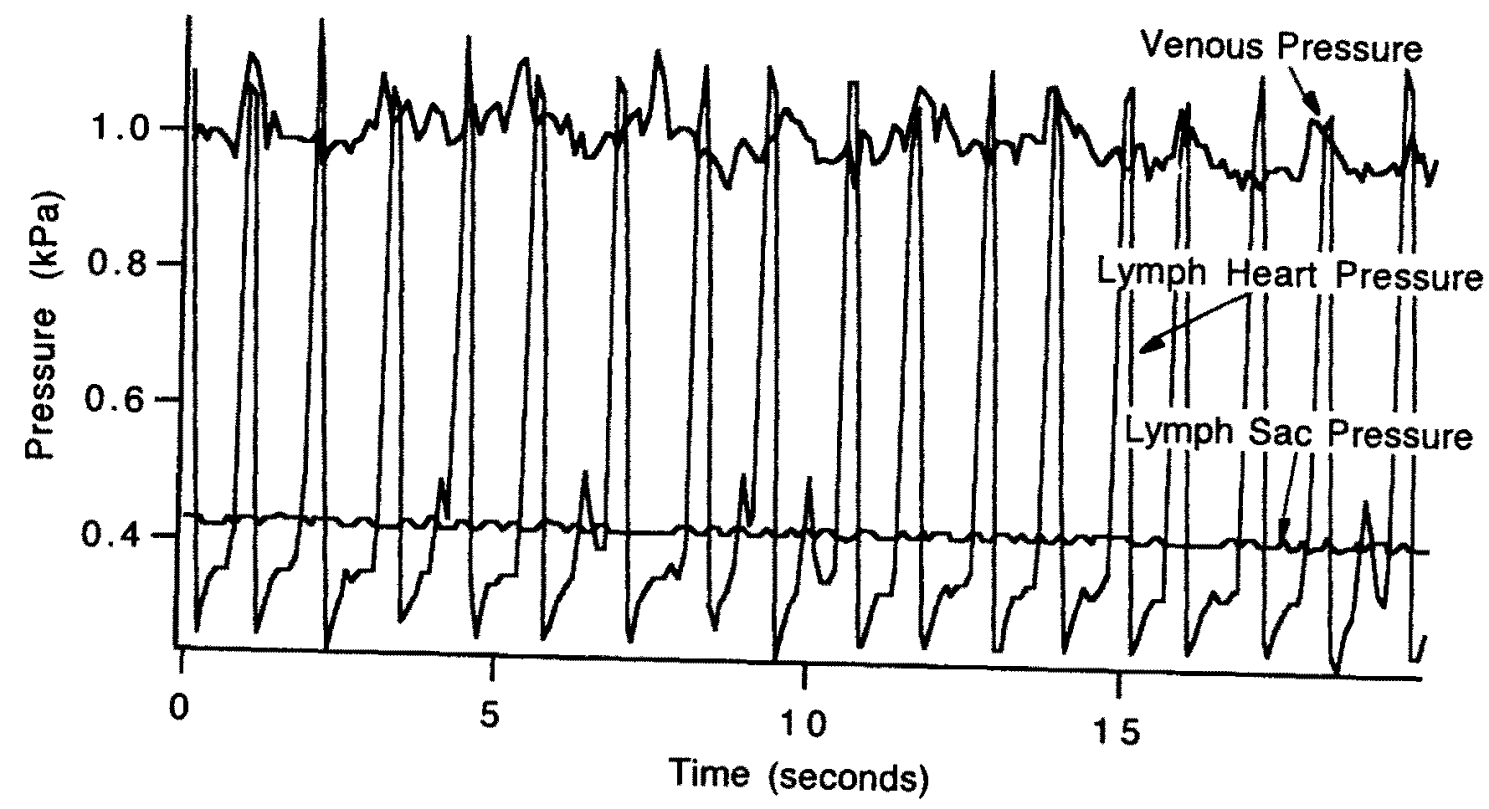

Figure 1. Interfemoral lymph sac, lymph heart and venous pressure against time in a $306 \mathrm{~g}$ toad at rest. 
The lymph heart pressure trace demonstrates that the range of pressures produced during contraction and relaxation overlap and exceed the pressure difference between the interfemoral lymph sac and the venous circulation. This enables lymphatic fluid to flow from the sac into the heart and to flow into the circulatory system down a temporary pressure gradient near the peak of contraction.

When the pressure of the interfemoral lymph sac was increased in a $282 \mathrm{~g}$ toad by infusion of saline the traces in figures $2 a$ and $2 b$ were produced. Infusion of saline (volume $=8 \%$ body mass) began at $t=5$ minutes at the rate of $10 \mathrm{ml} \mathrm{min}^{-1}$ and ended 2.25 minutes later.

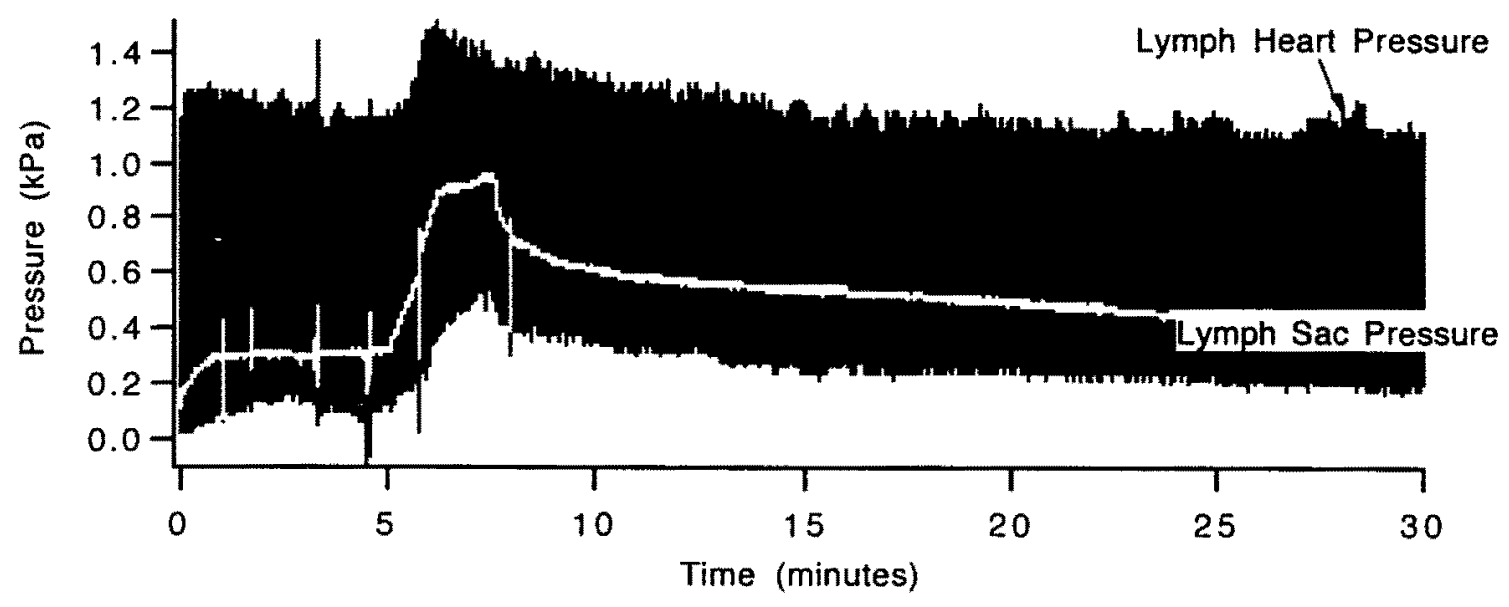

Figure 2a. Lymph heart and lymph sac pressure during infusion experiment 


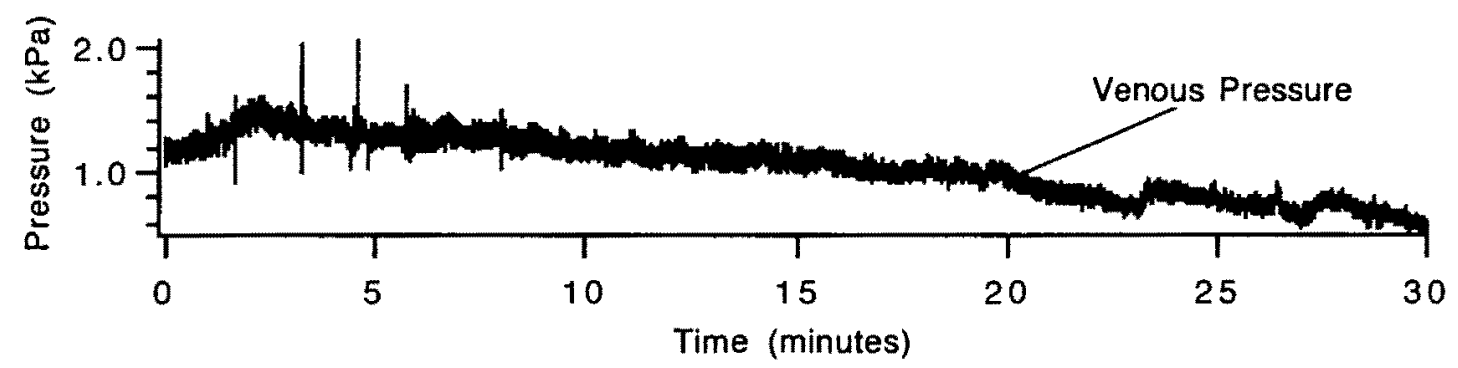

Figure $2 \mathrm{~b}$. Venous pressure in the ventral abdominal vein during infusion experiment.

Control values for peak systolic pressure were $1.34 \pm 0.19 \mathrm{kPa}( \pm$ S.E.; $\mathrm{n}=8)$, and $0.029 \pm 0.23 \mathrm{kPa}( \pm$ S.E.; $\mathrm{n}=8)$ for diastolic pressure.

Statistically significant $(\mathrm{p}<0.05)$ positive correlations were observed between systolic pressure and lymph sac pressure in 5 out of 8 individuals. These correspond to individuals with regression coefficients (Pr) greater than 0.30 . 


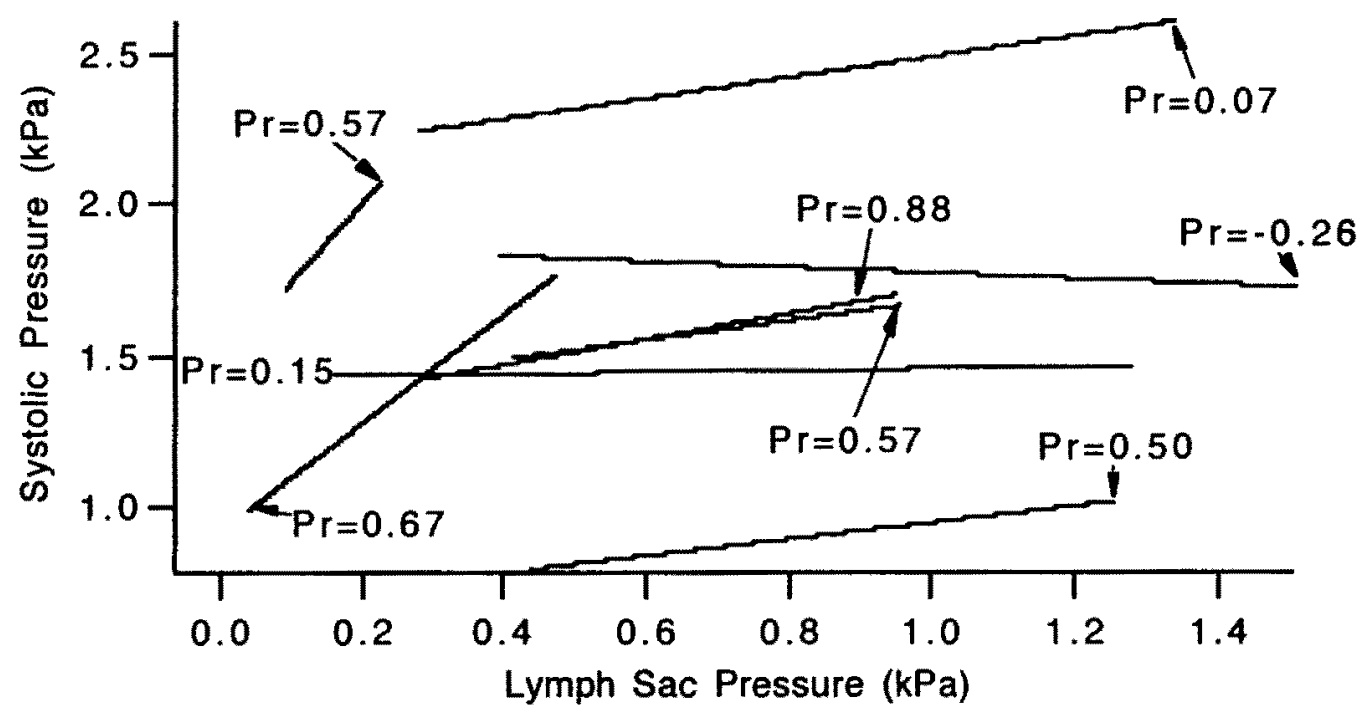

Figure 3, Systolic pressure and lymph sac pressure during infusion.

Statistically significant positive correlations were observed between diastolic pressure and lymph sac pressure in all animals examined.



Figure 4. Diastolic pressure and lymph sac pressure during infusion. 
In addition, in 7 out of 8 animals, diastolic pressure slopes were greater than systolic pressure slopes.

Table 1. Diastolic and systolic pressure slopes (Heart kPa/lymph sac $\mathrm{kPa}$ ) during infusion $\quad\left({ }^{*}\right.$ represents statistically non-significant slopes).

$\begin{array}{ccc}\text { n } & \text { Diastolic Pressure Slope } & \text { Systolic Pressure Slope } \\ 1 & 5.2 & 0.57 \\ 2 & 0.66 & 0.41 \\ 3 & 1.3 & 0.026^{*} \\ 4 & 0.24 & 0.093^{*} \\ 5 & 0.94 & 1.8 \\ 6 & 0.43 & 0.27 \\ 7 & 0.34 & 0.31 \\ 8 & 0.83 & 0.34^{*}\end{array}$

The lymph heart pressure traces were then differentiated and the maxima $(\mathrm{dP} / \mathrm{dt} \max )$ and minima $(\mathrm{dP} / \mathrm{dt} \mathrm{min})$, representing the most rapid increases in pressure and the most rapid decreases in pressure respectively, were regressed with lymph sac pressure in figures 5 and 6. 


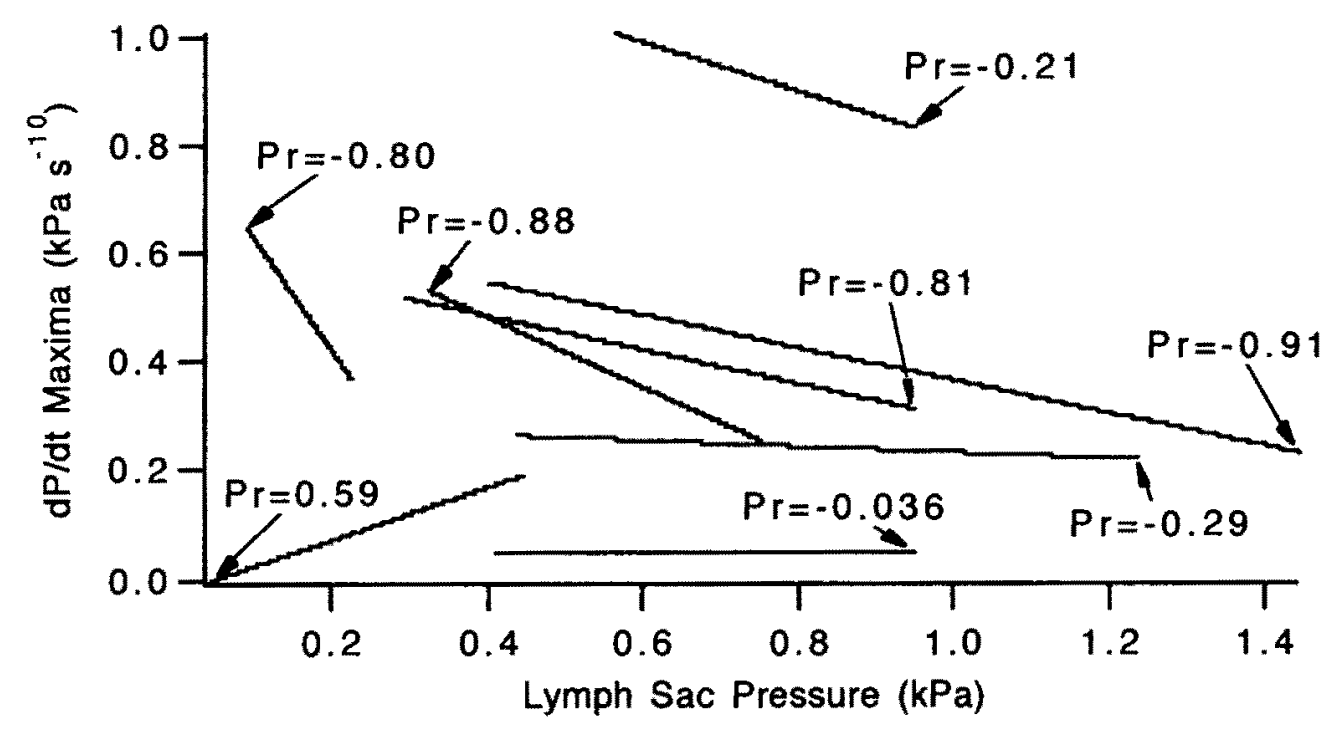

Figure 5. The most rapid increases in lymph heart pressure regressed with lymph sac pressure.

A significant negative correlation was observed in 6 out of 8 animals between the maximal rate of pressure increase and increasing lymph sac pressure. Regression coefficient $(\mathrm{Pr})$ values less than 0.30 are not statistically significant $(p<0.05)$. 




Figure 6.The most rapid decreases in lymph heart pressure regressed with lymph sac pressure.

A significant positive correlation was observed in 5 out of 8 animals between maximal rates of pressure decrease in the heart and increasing lymph sac pressure. Regression coefficient $(\mathrm{Pr})$ values less than 0.30 are not statistically significant $(\mathrm{p}<0.05)$.

The relation between systolic pressure and maximal rates of pressure increase was also examined and is described in figure 7. Significant positive correlations between systolic pressure and maximal rates of lymph heart pressure increases are observed in 4 animals. 




Figure 7. Systolic pressures regressed with maximal rates of lymph heart pressure increases.

Significant negative correlations are seen in $\mathbf{2}$ animals, and the remaining 2 animals demonstrate no statistically significant correlation.

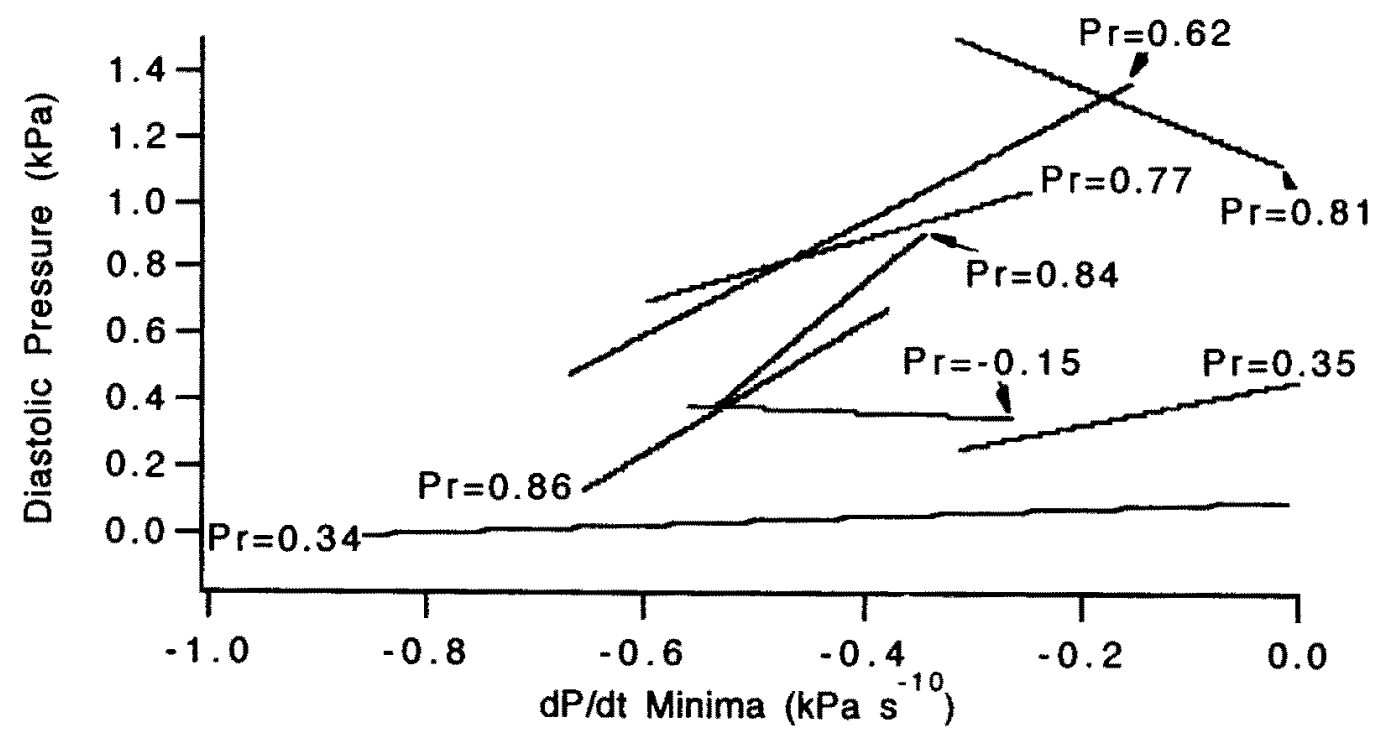


Figure 8. Diastolic pressure regressed with maximal rates of lymph heart pressure decreases.

Diastolic pressure exhibited a positive correlation to maximal rates of lymph heart pressure decreases in 6 toads examined. One toad demonstrated a statistically significant negative correlation between diastolic pressure and maximal rate of pressure decrease and the remaining animal showed no statistically significant correlation.

Toads with both posterior lymph hearts cannulated were examined to see whether lymph hearts on the same side (denoted by: a) or on the opposite side from the site of lymph sac cannulation (denoted by:b) respond differently to increased interfemoral lymph sac pressure. The results for 4 toads are summarized in table 2 , and asterisks * denote statistically non-significant slopes.

Table 2. Left and right lymph heart pressure correlation slopes.

Diastolic Pressure Diastolic Pressure Systolic Pressure SystolicPressure

$\begin{array}{ccccc}\mathrm{n} & \text { Slope a } & \text { Slope b } & \text { Slope a } & \text { Slope b } \\ 1 & 1.3 & 0.80 & 0.49 & 0.24 \\ 2 & 0.24 & 0.98 & -0.26^{*} & 0.46 \\ 3 & 0.94 & -0.67 & 0.67 & -0.034^{*} \\ 4 & 1.53 & 0.38 & 4.06 & -0.40\end{array}$


The effect of increased lymph sac pressure on lymph heart rate was examined and no statistically significant changes in heart rate were observed during or after infusion.



Figure 9. Lymph heart rate during infusion experiments.

The heart rate prior infusion was $51.6 \pm 2.76$ beats per minute, $50.2 \pm 3.48$ beats per minute during infusion and $48.6 \pm 2.36$ beats per minute after infusion. 


\section{DISCUSSION}

The results indicate that the interfemoral lymph sac pressure directly affects lymph heart pressure. Given the anatomical continuity between lymph sacs and lymph hearts, and the aggregation of pores in the lymph sac walls with proximity to the posterior lymph hearts as previously described, this coupling of pressure is expected. Fluid infused into the interfemoral lymph sac flows into the iliac lymph sac which contain the posterior lymph hearts. The posterior lymph hearts, which are suspended to the walls of the iliac lymph sac by radiating connective tissue attachments become exposed to an increased external pressure.

A rise in lymph sac pressure led to a proportionally higher increase in diastolic pressure than systolic pressure. As the heart relaxes following contraction, the ventricle fills until the diastolic pressure approximates that of the surrounding fluid. A point is reached where lymph sac and lymph heart pressure equilibrate and fluid no longer moves into the heart. The pressure at which this occurs, corresponding to minimum diastolic pressure, is dependent on iliac lymph sac pressure. As lymph sac pressure dictates the pressure at which pressure minimum diastolic pressure occurs, a tight correlation between the two is expected.

Peak systolic pressure of the posterior lymph hearts increased with rising lymph sac pressure. This represents an increase in the maximal pressure reached during contraction, but does not indicate whether more work is being performed by the heart. In order to determine the work done, it is necessary to measure the output of the heart as was done in Starling's experiments. However, peak systolic pressure was found to be directly proportional to stroke volume in experiments conducted on 
the posterior lymph hearts of Bufo marinus (Jones et al. manuscript, 1996). This suggests that peak systolic pressure can be used as an indirect indicator of the work being done by the heart. A further complication arises when considering that the rise in systolic pressure may be a direct result of elevated diastolic pressure. The lymphatic fluid is essentially incompressible at biological pressures and it is possible that a contraction of equivalent force results in a higher systolic pressure when the diastolic pressure is raised. In this way, a higher systolic pressure may not necessarily reflect increased stroke volume by the heart.

An increase in lymph sac pressure led to a decrease in the maximum rate of systolic pressure development. This suggests that the lymph hearts may have become over distended by excessive filling such that contraction was impeded. The afferent pores contain valves that prevent movement of fluid from the heart to the lymphatic system, and as such provide no protection against fluid moving in at artificially high pressure. The fact that the rapidity of systolic pressure development decreased when lymph sac pressure was elevated provides evidence that the load on the heart was increased but that the hearts were not necessarily responding to this load by ejecting the fluid any more vigorously. It is possible that the lymph sac pressure was experimentally raised well above physiological levels which disnupted optimal contractions. Diastolic pressure decreases were more rapid with increased lymph sac pressure indicating that the filling of the hearts was enhanced. The filling of the lymph hearts is passive, and under higher pressure, this occurs more rapidly.

The heart rate of the posterior lymph hearts remained unchanged during the infusion experiments indicating that lymph heart rate regulation is insensitive to high lymph sac pressure. Decreases in lymph heart rate have been observed with 
dehydration (Jones, 1992; Middler, 1968) and during periods of elevated systolic pressure as described in the pulmocutaneous baroreceptor feedback response (Crossley, 1995). Lymph heart rate regulation seems to involve the monitoring of arterial pressure such that blood volume can be adjusted in part by regulating the flow of fluid from the lymphatic system via lymph hearts into the vasculature. If the primary physiological role of the lymph hearts is to recruit fluid from the lymphatic space into the vasculature, then the sensitivity of lymph heart rate to lymph sac pressure may be unnecessary. In addition, physical movement by the animal probably leads to large transient changes in the lymph sac pressures which would make lymph sac pressures a difficult regulatory stimulus for lymph heart rate.

In the experiments where both posterior lymph hearts were examined simultaneously, the sample size was too small to allow for any definitive conclusions to be made. However, 3 out of 4 diastolic pressure increases were higher when the infusion was made on the same side of the lymph heart being examined. Infusions were made into the interfemoral lymph sac from which fluid would have to move into the iliac lymph sac before entering the lymph hearts. Previous experiments have shown that the number of pores in the lymph sac walls increases with proximity to the hearts (Jolly 1946) and it is possible that the flow of fluid to individual lymph hearts may be unequal within the same lymph sac.

The compliance measurements indicate that the range of compliances observed in the lateral and interfemoral lymph sacs of Bufo marinus are considerably higher than compliance measurements previously made in snakes. Lillywhite's (1993) measurements ranged from $1.0 \times 10^{-5} \mathrm{ml} \mathrm{kPa}^{-1}$ to $1.3 \times 10^{-4} \mathrm{ml} \mathrm{kPa}^{-1}$ for arboreal and terrestrial snakes respectively. In comparison the lymph sac compliances 
ranged from $1.2 \mathrm{ml} \mathrm{kPa}^{-1}$ in the lateral lymph sac to $0.62 \mathrm{ml} \mathrm{kPa}^{-1}$ in the interfemoral lymph sac in Bufo marinus. Arboreal snakes exhibit lower compliance when compared to terrestrial species, which may help prevent gravitational edema, and similarly in the lymph sacs examined, the interfemoral lymph sac which is closer to the posterior lymph heart had a lower compliance than the lateral lymph sac. A lower compliance in the sacs more proximal to the lymph hearts may facilitate the movement of lymph to those hearts.

In conclusion, statistically significant positive correlations were found between lymph sac pressure and systolic pressure. Whether this indicates that the lymph hearts are responding actively to an increased load remains undetermined in these experiments. The work being performed by the hearts as measured by output would indicate the presence of an active response, and this would be a beneficial continuation of this research. 


\section{LITERATURE CITED}

Baldwin, A. 1993. Regulation of water balance between blood and lymph in the frog, Rana pipiens. Lymphology. 26:4-18.

Baustian, M. 1988. The contribution of lymphatic pathways during recovery from hemorrhage in the toad Bufo marinus. Physiol.Zool. 61:555-563.

Boutilier, R.G., D.J. Randall, G. Shelton, and D.P. Toews. 1979. Acid-base relationships in the blood of the toad Bufo marinus. I. The effects of environmental $\mathrm{CO}_{2}$. J. Exp. Biol. 82: 331-344.

Braun-Menendez, E., et V.G. Foglia. 1939. Biologie et pharmacologie des coeurs lymphatiques des batraciens. Arch. Int. Pharmacodyn. 64:273-307.

Brekke, D.R., S.D. Hillyard, and R.M. Winokur. 1991. Behavior associated with the water absorption response by the toad Bufo punctatus. Copeia 16:393401 .

Carter, D. 1979. Structure and function of the subcutaneous lymph sacs in the anura (Amphibia). J. Herpet. 13:321-327.

Christensen, C.U. 1975. Effects of dehydration, vasotocin, and hypertonicity on net water flux through the isolated, perfused pelvic skin of Bufo bufo bufo (L.) Comp. Biochem. Physiol. 51A:7-10.

Christensen, C.U. 1975. Correlation between net water flux, osmotic concentration of the interstitial fluid, and osmotic permeability of the isolated skin of Bufo bufo bufo (L.). J. Comp. Physiol.96:95-100. 
Christensen, C.U. 1974. Effect of arterial perfusion on net water flux and active sodium transport across the isolated skin of Bufo bufo bufo (L.). J. Comp. Physiol.93:93-104.

Conklin, R.E. 1930a. The formation and circulation of lymph in the frog I. The rate of lymph production. Am. J. Physiol. 95: 79-90.

Conklin, R.E. 1930b. The formation and circulation of lymph in the frog II. Blood volume and pressure. Am. J. Physiol. 95: 91-97.

Conklin, R.E. 1930c. The formation and circulation of lymph in the frog III. The permeability of the capillaries to protein. Am. J.Physiol. 95: 98-110.

Crossley, D.A. 1995. The role of pulmocutaneous baroreceptors in the control of lymphatic heart rate in the toad Bufo marinus. Master's thesis Portland State University.

Ecker, A. 1889. The Anatomy of the Frog. (Translated by J. Haslem). Oxford: Clarendon Press.

Ewer, R.F. 1952. The effects of posterior pituitary extracts on water balance in Bufo carens and Xenopus laevis, together with some general considerations of anuran water economy. J. Exp. Biol. 29:429-439.

Feder, M.E. and W.W. Burggren. 1992. Environmental Physiology of the Amhibians. Chicago: The University of Chicago Press.

Foglia, V.G. 1941. Cause of death of toads after destruction of their lymph hearts. Proc. Soc. Exp. Biol. Med. 46:598-601.

Gamperl, A.K., J.M.Jones, D.P. Toews, and A.P.Farrell. 1995. Direct measurement of flow from the posterior lymph heart of the toad Bufo marinus. Physiol. Zool. 68:60. 
Hillman, S.S. and R.W. Sommerfeldt. 1981. Microspheres studies of amphibian systemic blood flow redistribution during dehydration, hypovolemia, and salt load. J. Exp. Zool. 218:305-308.

Hillman, S.S., A. Zygmunt, and M. Baustian. 1987. Transcapillary fluid forces during dehydration in two amphibians. Physiol. Zool. 60:339-345.

Hillman, S.S., and B. Schimpf. 1994. Renal responses to blood volume expansion of varying osmotic concentration in two species of amphibian, Bufo marinus and Rana catesbeiana. Physiol. Zool. 67:995-1005.

Jolly, J. 1946. Recherches sur le système lymphatique des batraciens. Arch.

D'Anatomie Microscopique. 36(1):3-44.

Jones, J.M., A.K. Gamperl, A.P. Farrell, and D.P. Toews. 1996. Direct measurement of flow from lymph hearts of hydrated and dehydrated toads (Bufo marinus). Manuscript.

Jones, J.M.,L.A. Wentzell, and D.P. Toews. 1992. Posterior lymph heart pressure and rate in the toad Bufo marinus in response to hydrated and dehydrated conditions. J. Exp. Biol. 169:207- 220.

Jones, R. 1978. Rapid water uptake in Scaphiopus couchi toadlets. Physiol. Zool.51: 51-55.

Kampmeier, O.F. 1969. Evolution and Comparative Morphology of the Lymphatic System. Springfield, 111. Thomas.

Lillywhite, H.B. 1993. Subcutaneous compliance and gravitational adaptation in snakes. J. Exp. Zool. 267:557-562.

Liu Zhi-yu, and J.R. Casley-Smith. 1989. The fine structure of the amphibian lymph heart. Lymphology. 22:25-30. 
Mahany, T.M., and R.H. Parsons. 1978. Circulatory effects on osmotic water exchange in Rana pipiens. Am. J. Physiol. 234:R172- R177.

Manning, R.D.J. and A.C. Guyton. 1980. Dynamics of fluid distribution between the blood and interstitium during overhydration. Am. J. Physiol. 238:645-651.

McClanahan, L. and R. Baldwin. 1969. Rate of water uptake through the integument of the desert toad, Bufo punctatus. Comp. Biochem. Physiol. 28:381-389.

Middler, S.A., C.R. Kleeman, and E. Edwards. 1968. Lymph mobilization following acute blood loss in the toad, Bufo marinus. Comp. Biochem. Physiol. 24:343-353.

Morris, J.L. 1981. Structure and function of ciliated peritoneal funnels in the toad kidney (Bufo marinus). Cell Tissue Res. 217:599-610.

Muller, J. 1833. On the existence of four distinct hearts, having regular pulsations, connected with the lymphatic system in certain amphibious animals. Philos. Trans. R. Soc. Lond. 1:89-94.

Noda, K. 1968. Osmometric and volumetric properties of the peritoneal surface, presumable from the change in activity of the lymph heart in the toad. Kurume Med. Journal. 15:179-192.

Parsons, G.G., L.A. Wentzell, J.M. Jones, and D.P. Toews. 1994. The role of arginine vasotocin in the control of posterior lymph heart function in the toad Bufo marinus. Physiol. Zool. 67:515-525.

Parsons, R.H., V. McDevitt, V. Aggerwal, T. Leblanc, K. Manley, N. Kim, J. Lopez, and A.A. Kennedy. 1993. Regulation of pelvic patch flow in Bufo 
marinus : Role of bladder volume and ANG II. Am. J. Physiol. 264:R1260R1265.

Parsons, R.H., and F. Mobin. 1991. Water flow across the pectoral and ventral pelvic patch in Rana catesbeiana. Physiol. Zool. 64(3):812-822.

Patterson, S.W. and E.H. Starling. 1914. On the mechanical factors which determine the output of the ventricles. J. Physiol. 48:357-379.

Priestley, J. 1878. An account of the anatomy and physiology of the batrachian lymph-hearts. J. Physiol., Lond. 1:1-17.

Rodrigues, L. 1957. Lymph hearts in Rana . The Biol. Rev. 19:23-29.

Satoh, Y. 1980. On the fine structure of lymph hearts in amphibia and reptiles. Hearts and Heart-like Organs. 1:149-159.

Scholander, P., Hargens, A., and Miller, S. 1968. Negative Pressure in the Interstitial Fluid of Animals. Science 161(3839):321-328.

Shoemaker, V.H. 1965. The stimulus for the water-balance response to dehydration in toads. Comp. Biochem. Physiol. 15:81-88.

Shoemaker, V.H., and K.A. Nagy. 1977. Osmoregulation in amphibians and reptiles. Ann. Rev. Physiol. 39:449-471.

Smits, A.W. 1986. Accessory lymph sacs and body fluid partitioning in the lizard, Sauromalus hispidus. J. Exp. Biol. 121:165-177.

Smits, A.W., and R. Ilowite. 1989. Transcapillary fluid exchange in isolated toad hindlimbs. Faseb J. 3:A559.

Starling, E.H. 1918. Linacre Lecture, The Law of the Heart. London.

Starling, E.H. and M.B. Visscher. 1927. The regulation of the energy output of the heart. J. Physiol. 62: 243-261. 
Thorson, T. B. 1964. The partitioning of body water in Amphibia. Physiol. Zool. 37:395-399.

Wentzell, L.A., S.A. McNeil, and D.P. Toews. 1993. The role of the lymphatic system in water balance processes in the toad Bufo marinus (L.). Physiol. Zool. 66(3):307-321.

Yokota, S. and S.S. Hillman. 1984. Adrenergic control of the anuran cutaneous hydroosmotic response. Gen. Comp. Endocrinology. 53:309-314.

Zwemer, R.L., and U.G. Foglia. 1943. Fatal loss of plasma after lymph heart destruction in toads. Proc. Soc. Exp. Biol. Med. 53:14-17. 